\title{
PENYULUHAN PENGGUNAAN OBAT YANG BENAR DI JALAN M. SAID LOK BAHU, SAMARINDA
}

\author{
Sumarti Binti Amrin \\ Program Studi S1 Farmasi Stikes Dirgahayu Samarinda \\ Jln. Pasundan No.21 Kelurahan Jawa, Kecamatan Samarinda Ulu \\ Kalimantan Timur, 75122.085247027350 \\ e-mail : inceborneo@gmail.com
}

\begin{abstract}
ABSTRAK
Masyarakat Indonesia pada umumnya masih awam dengan kesehatan lingkungan termasuk obat-obatan. Faktor rendahnya pendidikan khususnya di pedesaan dan juga perkotaan di kantong-kantong kemiskinan penyakit sangat mudah menular karena pemberian obat yang seadanya dan lebih percaya pada pengobatan tradisonal. Penyuluhan menggunakan leaflet, menjelaskan cara penggunaan obat, petunjuk dan cara pakai yang telah ditentukan oleh tenaga kesehatan, dan cara buang obat seperti obat yang telah rusak tidak akan bermanfaat, bahkan dapat menjadi racun dalam tubuh serta menjelaskan cara penggunaan obat tetes mata/ salep mata, obat tetes telinga, obat tetes hidung, obat oral/ obat minum dan suppositoria. Peserta penyuluhan masih kurang tepat dalam menggunakan obat terutama cara penggunaan obat dan peserta penyuluhan tidak mengetahui cara membuang obat yang sudah kadaluarsa dengan cara yang benar. penyuluhan telah terlaksana dengan baik dan mendapatkan respon yang baik dari peserta, serta memberikan manfaat kepada Warga Gg. Usaha. Peserta penyuluhan sebagian besar adalah bapak dan ibu rumah tangga.
\end{abstract}

\section{Kata Kunci : Penyuluhan, obat, Lok Bahu, Samarinda}

\section{ABSTRACT}

Indonesian people in general are still unfamiliar with environmental health, including medicine. Factors of low education, especially in rural and urban areas in pockets of poverty, are very contagious due to improper administration of drugs and more trust in traditional medicine. Counseling using leaflets, explaining how to use drugs, instructions and how to use that have been determined by health workers, and how to dispose of drugs such as drugs that have been damaged will not be useful, even can be toxic in the body and explain how to use eye drops / eye ointment, ear drops, nasal drops, oral medications / oral medications and suppositories. Participants in counseling are still not quite right in using drugs, especially how to use drugs and counselors do not know how to dispose of expired drugs the right way. counseling has been done well and get a good response from the participants, as well as providing benefits to residents of Gg. Usaha. Participants in the extension were mostly fathers and housewives.

\section{Key Words : Counseling, medicine, Lok Bahu, Samarinda}




\section{PENDAHULUAN}

Masyarakat Indonesia pada umumnya masih awam dengan kesehatan lingkungan termasuk obat. Faktor rendahnya pendidikan khususnya di pedesaan dan juga perkotaan di kantong-kantong kemiskinan penyakit sangat mudah menular karena pemberian obat yang seadanya dan lebih percaya pada pengobatan tradisonal. Selain itu pula ada segelintir orang yang menggunakan obat untuk tujuan-tujuan tertentu yang dapat membahayakan jiwanya sendiri maupun orang lain. Sudah banyak korban atas pengobatan tradisonal dan penggunaan obat yang tidak benar mengakibatkan kematian dan pemerintah sudah mencoba mencegah agar jangan sampai terulang hal yang sama namun selalu muncul dari waktu ke waktu bersamaan dengan meningkatnya penggunaan narkotika.

Permasalahan tersebut dapat saja dihindari dengan adanya pemahamanpemahaman tentang kesehatan dari unsur pemerintah, swasta atapun perseorangan yang ingin agar masyarakat lebih mengerti pentingnya kesehatan dan pencegahan terhadap penyakit serta juga mengurangi korban jiwa atas penggunaan obat yang salah. Oleh karena itu perlunya pemahaman penggunaan obat yang benar di kalangan masyarakat.

Obat adalah zat yang digunakan untuk diagnose, mengurangi rasa sakit serta mengobati atau mencegah penyakit pada manusia. Pemakaian obat banyak sekali yang digunakan untuk berbagai penyakit. Pengertian obat itu sendiri merupakan bahan yang hanya dengan takaran tertentu dan penggunaan yang tepat dapat dimanfaatkan untuk mencegah penyakit, menyembuhkan atau memelihara kesehatan dan masyarakat juga harus mengerti dengan penggolongan obat seperti Obat Bebas, Obat Bebas Terbatas, Obat Keras, Obat Psikotropika, Obat Narkotika.
Masyarakat Jln. M. Said Lok Bahu, Gg. Usaha Samarinda berjumlah sekitar 25 orang. Dimana yang selama ini mereka belum mengerti pengguna obat yang benar. perlu mendapatkan perhatian khusus dan menjadi program Kemitraan Masyarakat Stikes Dirgahayu Samarinda.

\section{METODE}

Dalam kegiatan tersebut, tim pelaksana menyampaikan tujuan pelaksanaan kegiatan, jadwal kegiatan, dan kontribusi ibu-ibu arisan Gg.usaha serta masyarakat terhadap berlangsungnya kegiatan tersebut. Pihak kepala Arisan dan ketua RT menyambut positif dan sangat antusias dengan akan diadakannya kegiatan tersebut karena dirasa akan sangat bermanfaat dan belum pernah ada kegiatan sejenis sebelumnya. Rangkaian kegiatanpun disepakati untuk dilaksanakan di salah satu rumah warga arisan Gg. Usaha. Pelaksanaan penyuluhan penggunaan obat yang benar dimulai dengan membagikan leaflet, serta menjelaskan cara penggunaan obat yang benar, seperti menggunakan obat sesuai petunjuk dan cara pakai yang telah ditentukan oleh tenaga kesehatan, dan buang obat dengan benar seperti obat yang telah rusak tidak akan bermanfaat, bahkan dapat menjadi racun dalam tubuh. Menjelaskan cara penggunaan obat tetes mata/ salep mata, obat tetes telinga, obat tetes hidung, obat oral/ obat minum dan suppositoria. Kemudian diskusi dan Tanya jawab. Arahan dari kegiatan ini yaitu untuk memotivasi para ibu-ibu dan bapak-bapak, dan sebagian masyarakat yang hadir pada kegiatan untuk menjadi pelaku dan contoh bagi masyarakat lain yang tidak hadir terkait dengan penggunaan obat yang baik, benar, dan rasional. Diharapkan para peserta yang hadir dapat menyampaikan ilmu yang diperoleh untuk disebarkan di 
lingkungan rumah mereka dan masyarakat.

\section{HASIL dan PEMBAHASAN}

Berdasarkan hasil kegiatan yang telah dilakukan selama pelaksanaan pengabdian kepada masyarakat pada penyuluhan penggunaan obat yang benar di Jln. M.Said Lok Bahu, Samarinda didapati hasil sebagai berikut ini :

1. Penyuluhan obat yang terlaksana dengan baik dan mendapatkan respon yang baik dari peserta penyuluhan, serta memberikan manfaat kepada warga gg. Usaha.

2. Yang mengikut penyuluhan sebagian besar adalah bapak dan ibu rumah tangga.

3. Peserta penyuluhan masih kurang tepat dalam menggunakan obat terutama cara penggunaan obat yang baik.

4. Pesrta penyuluhan tidak mengetahui cara membuang obat yang sudah expired/ kadaluarsa dengan cara yang benar.

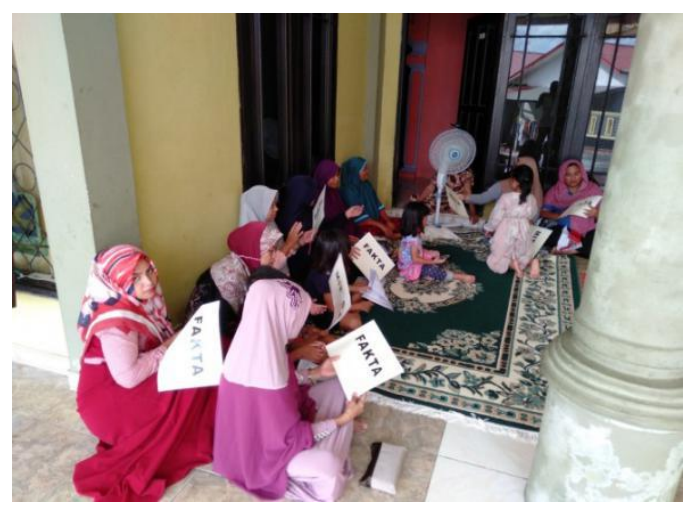

Gambar 2. Penyampaian Materi penyuluhan

\section{KESIMPULAN DAN SARAN}

Program Kegiatan Masyarakat (PKM) yang dilaksanakan pada tanggal 13 Januari 2019 bertempat di rumah salah satu warga di Jln. M. Said, Gang Usaha Lok Bahu, Samarinda. Sebagai bentuk pelaksanaan Tridharma
Perguruan Tinggi Stikes Dirgahayu Samarinda dengan judul Penyuluhan Penggunaan Obat yang Benar, penyuluhan telah terlaksana dengan baik dan mendapatkan respon yang baik dari peserta, serta memberikan manfaat kepada Warga Gg. Usaha. Peserta penyuluhan sebagian besar adalah bapak dan ibu rumah tangga.

1. Peserta penyuluhan masih kurang tepat dalam menggunakan obat terutama cara penggunaan obat tersebut.

2. Peserta penyuluhan tidak mengetahui cara membuang obat yang sudah kadaluarsa dengan cara yang benar.

\section{Saran}

1. Peserta penyuluhan diharapkan agar benar-benar dapat mengaplikasikan ilmu yang telah didapat terutama dalam cara penggunaaan obat dengan sebaikbaiknya.

2. Peserta penyuluhan diharapkan dapat membuang obat yang sudah kadaluarsa dengan prosedur yang benar, sehingga tidak sampai mencemari lingkungan sekitar.

\section{UCAPAN TERIMA KASIH}

Saya ucapkan rasa terima kasih sebesar-besarnya kepada

Lembaga Penelitian dan Pengabdian Kepada Masyarakat (LPPM) Stikes Dirgahayu Samarinda yang telah mendanai berlangsungnya program ini, kepada Pak RT beserta jajaran yang banyak terlibat dan membantu pelaksanaan Penyuluhan ini.

\section{DAFTAR PUSTAKA}

H. A. Syamsuni (2016), Ilmu Resep. Jakarta: EGC,2006.

Moh. Anief (2010), Ilmu Beracik Obat, Gadjah Mada University Press. 
Modul I (2008), Materi pelatihan Peningkatan Pengetahuan dan Keterampilan Memilih obat, Direktorat Bina Penggunaan Obat Benar/ Rasional, Depkes RI.

Bina Kefarmasian dan Alkes Depkes RI.(2008). Materi Pelatihan Peningkatan Pengetahuan dan Keterampilan Memilih Obat Bagi Tenaga Kesehatan, Jakarta.

Theodorus. dr ( 1996).Peresepan Obat, EGC, Jakarta. 